\title{
Nd:YAG Laser Hyaloidotomy for the Treatment of Acute Subhyaloid Hemorrhage: A Comparison of Two Cases
}

Jens Heichel • Elisabeth Kuehn · Astrid Eichhorst · Thomas Hammer •

Iris Winter

To view enhanced content go to www.ophthalmology-open.com

Received: November 16, 2015 / Published online: December 22, 2015

(c) The Author(s) 2015. This article is published with open access at Springerlink.com

\section{ABSTRACT}

Introduction: Subhyaloid hemorrhage, whether spontaneous or in the context of a Valsalva maneuver, can lead to an acute decrease in vision when located in the premacular region. Nd:YAG laser hyaloidotomy (NYLH) is a minimally invasive treatment option.

Methods: We examined two different clinical courses based on two case reports of NYLH. One case report described a 52-year-old female patient who presented with a painless decrease of vision to $20 / 200$. The fundoscopy verified a subhyaloid premacular hemorrhage. The precipitating event for the hemorrhage could not be determined, and a NYLH was performed 5 days after the event. The other patient was a 48-year-old man who suffered an acute visual decrease (hand motion) after developing a

Electronic supplementary material The online version of this article (doi:10.1007/s40123-015-0043-1) contains supplementary material, which is available to authorized users.

J. Heichel $(\bowtie) \cdot$ E. Kuehn · A. Eichhorst .

T. Hammer · I. Winter

Department of Ophthalmology, University Hospital

of Martin Luther University Halle-Wittenberg,

Halle (Saale), Germany

e-mail: jens.heichel@uk-halle.de migraine with vomiting. Fundoscopy showed a dense subhyaloid premacular hemorrhage. NYLH was performed 1 day after the hemorrhage. These clinical courses were documented based on fundus photographs, ultrasounds, and spectral-domain optical coherence tomography (SD-OCT).

Results: In both cases, there was an effect with approximately $2.2 \mathrm{~mJ}$ of laser energy. In the female patient, we observed a gradual but constant increase in vision. After 4 weeks, her vision improved to $20 / 20$. In the male patient, the vision increased to $25 / 20 \quad 1$ day after treatment. However, his vision returned to hand motion as he developed a diffuse vitreous opacification. Because of delayed reabsorption, vitrectomy was considered. Since the optical axis was clear with good vision, we decided against this surgery. Complete reabsorption took more than 3 months.

Conclusion: After NYLH for subhyaloid hemorrhage, pronounced vitreous body opacification could develop despite a rapid increase in vision, and requires close monitoring by the surgeon. Fundus photography and SD-OCT are suitable means for clinical course evaluations. 
Keywords: Nd:YAG laser; Nd:YAG laser hyaloidotomy; Premacular subhyaloidal bleeding; Valsalva maneuver; Vitreous hemorrhage

\section{INTRODUCTION}

Subhyaloid premacular hemorrhage usually leads to an acute and pronounced decrease in vision. Different mechanisms including vasoproliferative diseases (e.g., ischemic retinal venous thromboses or diabetic retinopathy), vascular anomalies (e.g., retinal macroaneurysms), or rare pathologies such as leukemia or Terson syndrome may cause these hemorrhages [1-4]. A Valsalva maneuver may also be a typical trigger, because an increase in intraabdominal/intrathoracic pressure may result in an increase in cranial pressure and consequently, an increase in intraocular venous pressure [5]. The absence of venous valves in the head/neck area favors this occurrence. Each mechanism could lead to a bleeding into the vitreoretinal interface. Due to a still attached posterior hyaloid membrane, a premacular hemorrhagic bubble will be formed leading to a decreased vision and/or a central scotoma. The visual acuity may decrease to the level of light perception [4]. Spontaneous reabsorption is possible. However, the time course is unclear. Preretinal bleeding can lead to the formation of epiretinal membranes [2], and there may also be changes in the retinal pigment epithelium or damage to the photoreceptors from the iron ions $[3,6]$. For this reason, prompt removal of the hemorrhage is important [7]. Various therapeutic approaches may be used, such as the intravitreal administration of $\mathrm{SF}_{6}$ gas or a pars plana vitrectomy [8-10]. Opening the posterior hyaloid membrane by laser (referred to as membranotomy) presents a minimally invasive option that had been previously described in the 1970s [11].

\section{CASE REPORT 1}

\section{History and Findings}

A 52-year-old female patient presented with an acute, painless decrease of vision in the right eye of 4 days duration. A history of a Valsalva maneuver could not be identified. The woman had been performing light physical labor in her garden when she suddenly noticed the deterioration in vision.

The best corrected visual acuity in the right eye was 20/200 and in the left eye 20/20. The patient was myopic (spherical equivalent in the right eye: $-5.5 \mathrm{D}$; left eye: $-6.5 \mathrm{D}$ ). There were no signs of other ophthalmological disorders. Ophthalmoscopy could detect a moderately pronounced subhyaloid hemorrhage in the right eye; however, no other pathologic findings were detected. The patient had arterial hypertension but was generally in good health.

After discussion of the therapeutic options (observation vs. surgical intervention), the patient requested immediate treatment. A Nd:YAG laser hyaloidotomy (NYLH) was offered. Before treatment, the findings were documented via fundus photography (Fig. 1a) and spectral-domain optical coherence tomography (SD-OCT). The SD-OCT assessed the accumulated blood in the premacular space separated by the posterior hyaloid membrane (Fig. 1b, c).

\section{Therapy}

A Q-switched, neodymium-doped yttrium aluminum garnet $\left(\mathrm{Y}_{3} \mathrm{Al}_{5} \mathrm{O}_{12}\right)$ laser (Nd:YAG 


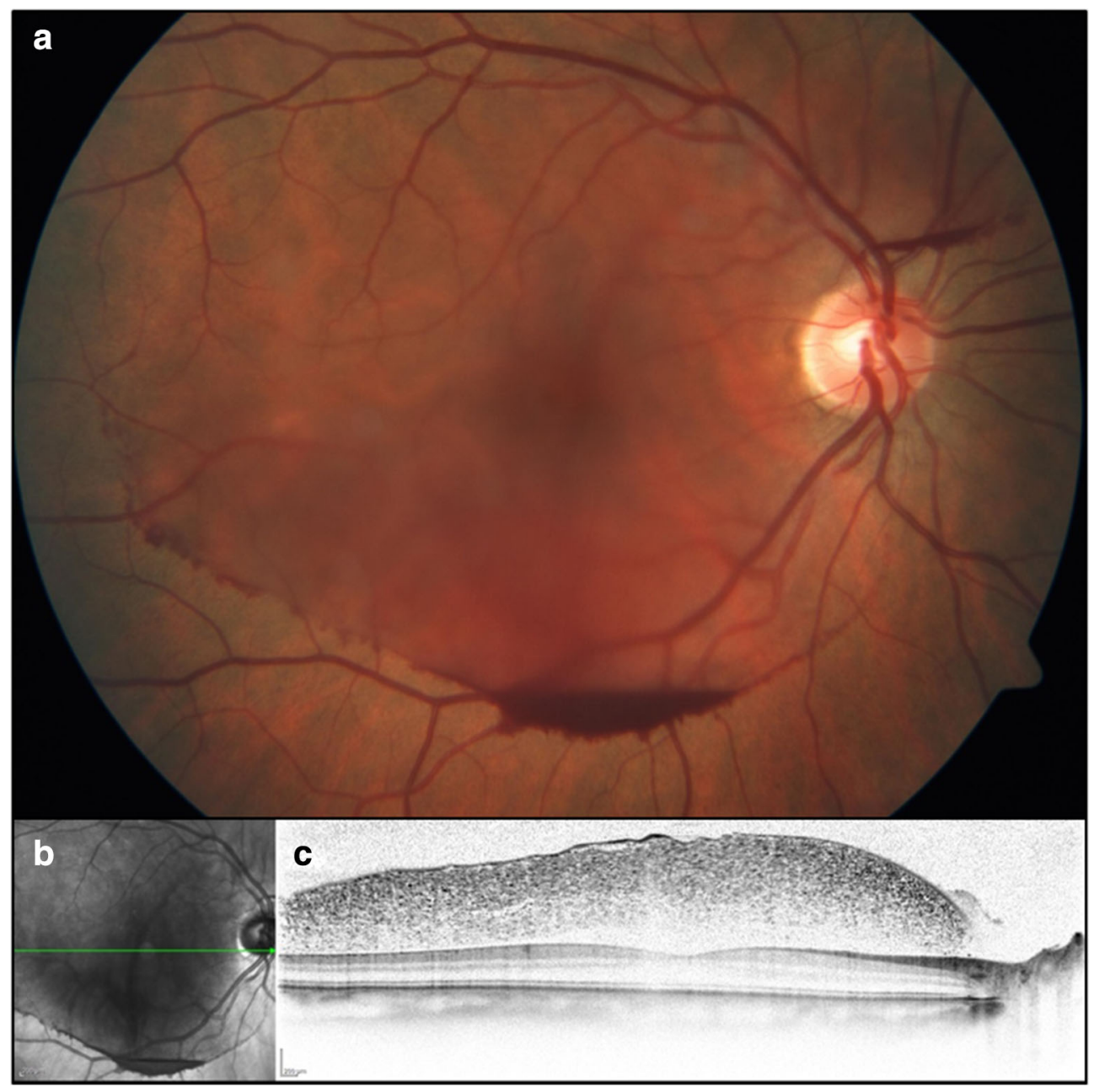

Fig. 1 Central fundus at first visit. a Fundus photography: typical "blood level" in the area of the inferior temporal vascular arch. b Infrared photograph (green line marks the respective

laser, $1064 \mathrm{~nm}$; Visulas IIplus ${ }^{\circledR}$, Zeiss, Oberkochen, Germany) was used for the procedure. The laser had a pulse duration of 2-3 ns with a spot size of $10 \mu \mathrm{m}$. The four-point aiming beam system was adjusted for an anterior focus. This was meant to prevent damage to the retina from the generated shockwave. The Area Centralis ${ }^{\circledR}$ (Volk Optical Inc., Mentor, OH, USA) was used as the contact lens, because it allowed for good visualization of the central fundus up to the border of the temporal vessel arches. The magnification for localization of the SD-OCT image of the c). $\mathbf{c}$ Spectral-domain optical coherence tomography shows a subhyaloid accumulation of blood. The macula shows a normal configuration

laser applications was 0.94. After medical mydriasis and topical anesthesia of the conjunctiva, we started at an energy level of $1.2 \mathrm{~mJ}$. The laser was employed just above the inferior apex of the bleeding. With this process, we observed no effects at the hyaloid membrane. With increased energy, the blood bubble started to undulate. A rupture was finally achieved at $2.2 \mathrm{~mJ}$. Immediately, the blood slowly started to spread into the vitreous body space. The cumulative energy used was $8.9 \mathrm{~mJ}$. 


\section{Clinical Course}

After 3 days, the best corrected vision in the right eye was 0.5. The subhyaloid premacular hemorrhage was barely detectable on fundoscopy
(Fig. 2a). Blood streaks identified the area of rupture from the laser (Fig. 2b). The SD-OCT was able to detect the remaining hemorrhage (Fig. 2c).

Four weeks after treatment, the vision had increased to 20/20. Residual blood could still

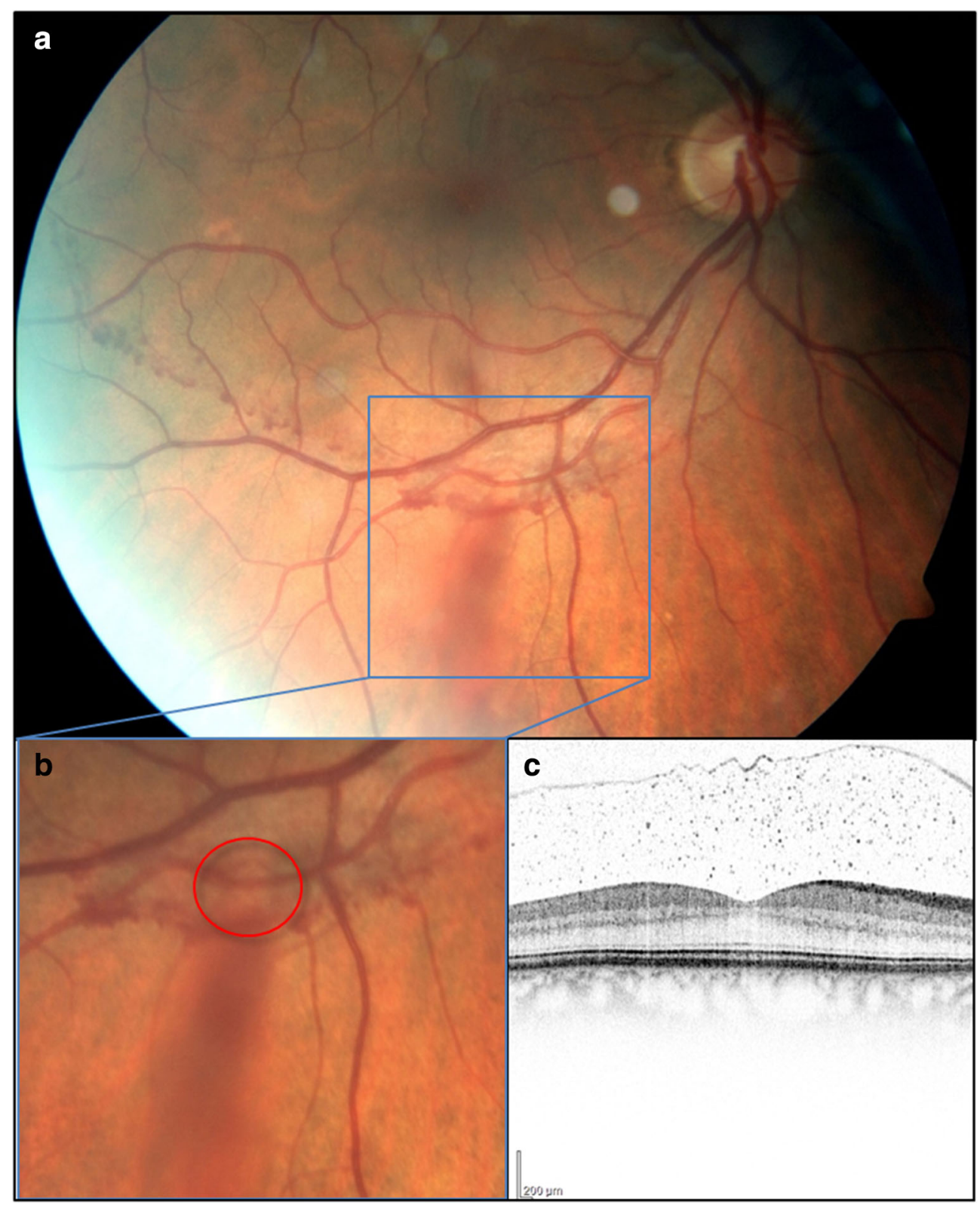

Fig. 2 Inferior temporal vascular arch 3 days after laser treatment. a Fundus photography shows a reduction in the premacular hemorrhage as well as remaining streaks of blood at the inferior temporal vessel arch. b Magnified fundus photograph with representation of the hyaloidotomy (red circle). c Spectral-domain optical coherence tomography of the macula: clear reduction of the subhyaloid opacification 


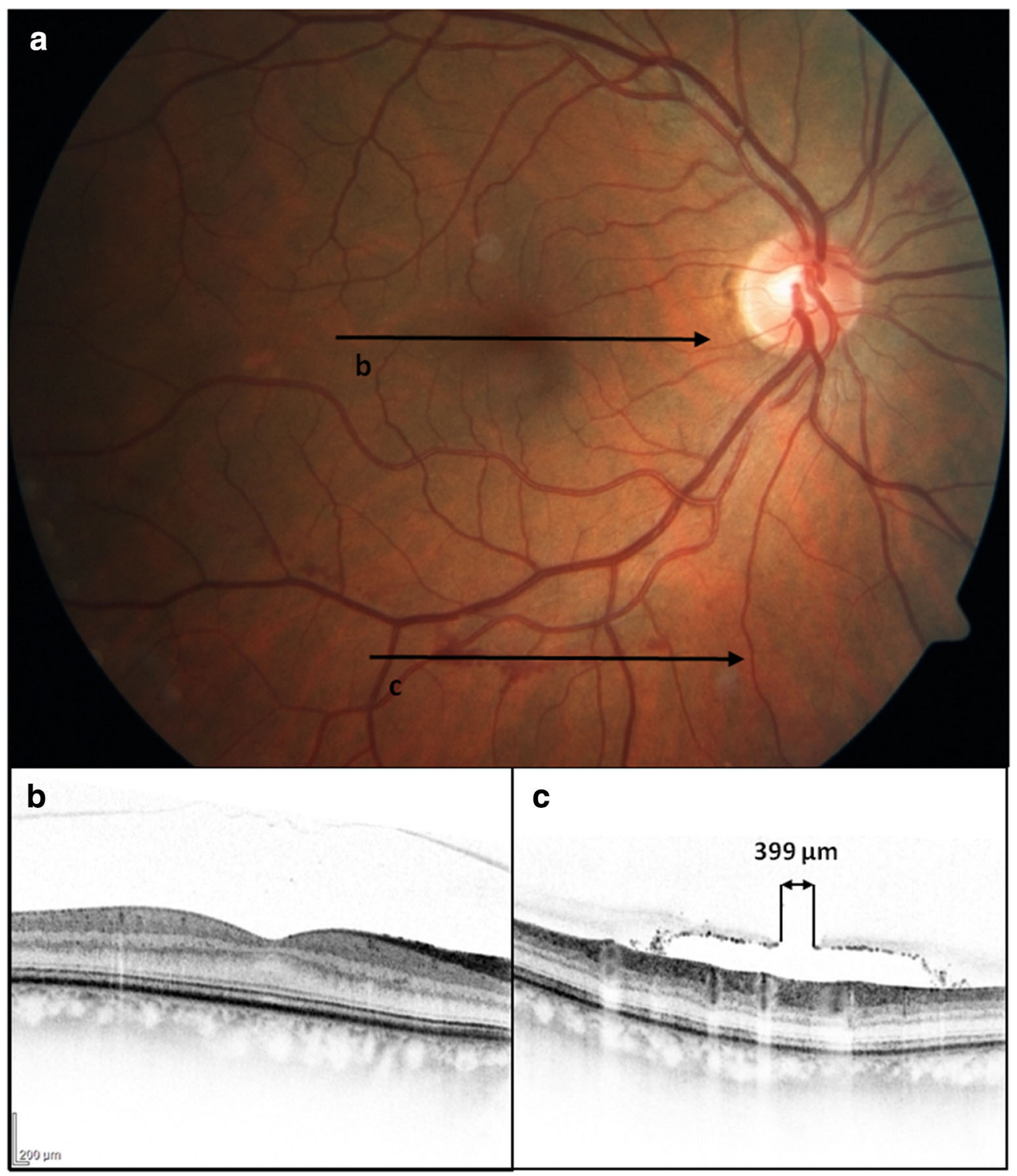

Fig. 3 Central fundus 4 weeks after laser treatment. a Fundus photography: discrete bleeding remained within the area of the inferior temporal vascular arch (the lines mark the respective localizations of the SD-OCT images of the $\mathbf{b}$ and $\mathbf{c}$. $\mathbf{b}$ SD-OCT of the macula: no subhyaloid opacifications were detectable. c SD-OCT of the hyaloidotomy: a 399- $\mu \mathrm{m}$ rupture of the posterior hyaloid membrane is recognizable. $S D-O C T$ spectral-domain optical coherence tomography be found in the area of the lower vascular arch (Fig. 3a). The SD-OCT could barely detect an opacification of the premacular space (Fig. 3b). At the site of the laser application, there was an opening of $399 \mu \mathrm{m}$ (Fig. 3c).

\section{CASE REPORT 2}

\section{History and Findings}

A 48-year-old male patient presented with an acute reduction of vision in his left eye 1 day 
after an episode of severe vomiting due to a migraine attack. During this episode, the patient performed several strong Valsalva maneuvers. Best corrected visual acuity in the right eye was $25 / 20$. His visual acuity in the left eye was hand motion at presentation. A dense and prominent subhyaloid premacular hemorrhage was seen on ocular examination. Otherwise, there were no pathological changes. After appropriate discussion of options, risks, and benefits, the patient elected to undergo an NYLH.

\section{Therapy}

The procedure was performed in the same way as described for the first case report. However, in this patient, no laser effect could initially be seen with a low-energy setting. After a gradual increase in energy, a rupture in the posterior vitreous cortex was observed. The energy amounted to $2.4 \mathrm{~mJ}$. Altogether, $12.3 \mathrm{~mJ}$ was used.

\section{Clinical Course}

On the first post-operative day, the vision had increased to 25/20. However, the patient reported a visual deterioration 1 week later. At this time, the visual acuity had decreased to hand motion. The subhyaloid blood masses had drained into the intravitreal cavity and had led to a diffuse opacification of the vitreous body (Fig. 4a-c). Because of delayed reabsorption, vitrectomy was considered. Since the optical axis was clear with good vision, we decided against this surgery. Over the next 4 weeks, the vision gradually increased to initial levels (Fig. 5).

\section{COMPLIANCE WITH ETHICS GUIDELINES}

All procedures were in accordance with the ethical standards of the responsible committee on human experimentation (institutional and national) and with the Helsinki Declaration of 1964, as revised in 2013. Informed consent was obtained from the patients for being included in the study.

\section{DISCUSSION}

Subhyaloid hemorrhage has been defined as bleeding into the vitreoretinal interface [7]. A premacular location worsens the clinical picture for the patient, and leads to an acute painless decrease in vision or a central scotoma. This bleeding usually develops in the context of retinal vasoproliferative disorders, such as venous thromboses or proliferative diabetic retinopathy [12, 13]. However, vascular malformations, Valsalva maneuvers, or traumata are also possible causes [13]. Terson syndrome or hematological disorders should also be considered in the differential diagnosis, since these may represent acute life-threatening situations $[14,15]$.

With our female patient (see "Case Report 1 "), this hemorrhage was likely a spontaneous (idiopathic) hemorrhage. Apart from myopia, she did not have any other causal factors. A typical Valsalva maneuver could not be determined from the history. It is possible that the initial physiological separation of the posterior vitreous body could have led to a type of rhexis bleeding from the smallest retinal vessels. Idiopathic mechanisms should be considered in the differential diagnosis [4]. The connections between the posterior vitreous membrane and the inner limiting 

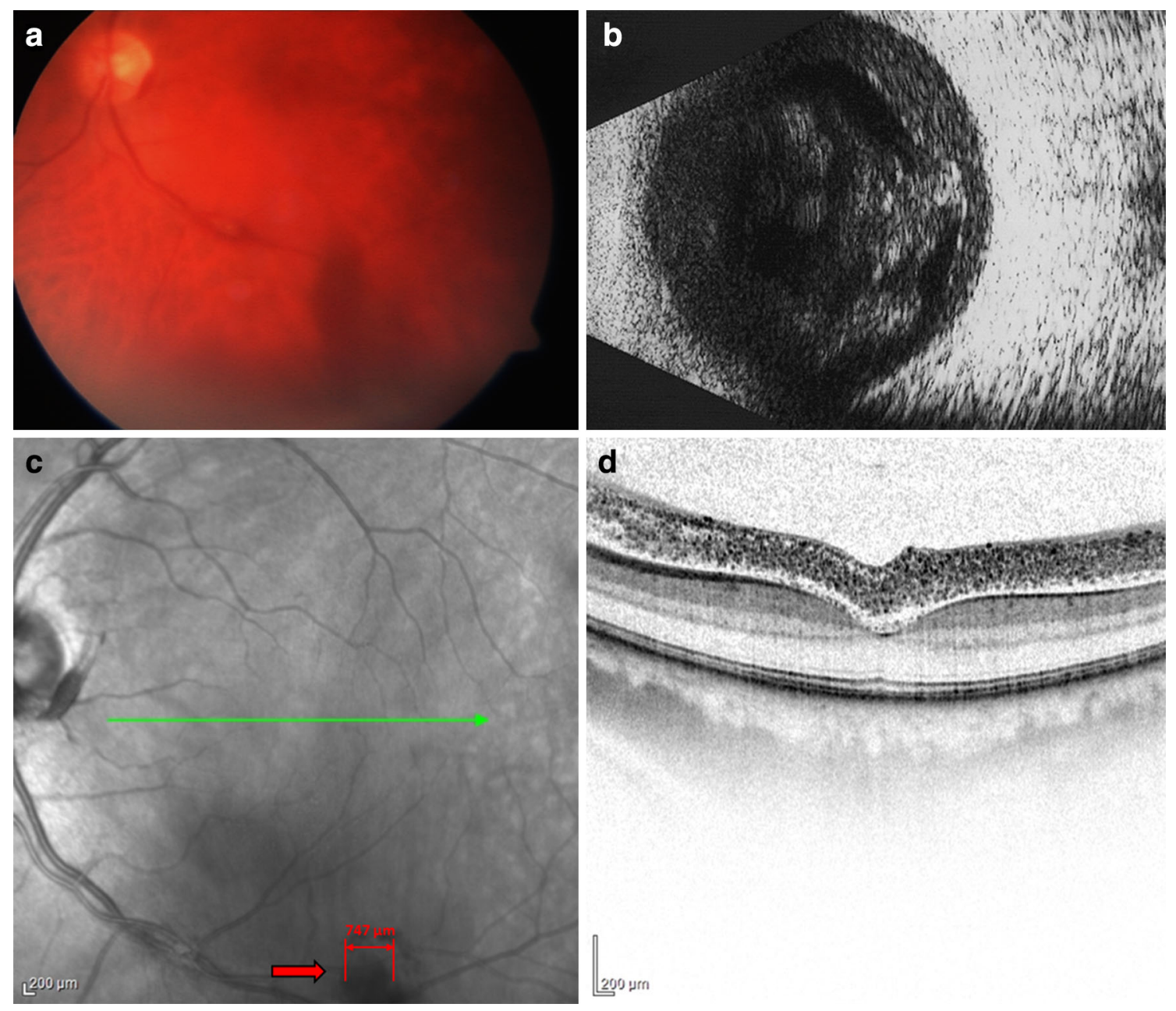

Fig. 4 Image documentations 1 week after surgery. a Fundus photography: streaky intravitreal blood can be detected that originated from the inferior temporal vascular arch. b Ultrasound B image: hemorrhage with subhyaloidal and intravitreal portions. c Infrared image: in the area of the laser application, a rupture of approximately $747 \mu \mathrm{m}$ in

membrane (Membrana limitans interna, MLI) can be very tough due to the anchoring fibrils (collagen II, hyalocytes $\leftrightarrow$ fibronectin, laminin $\leftrightarrow$ collagen IV of the MLI) and can cause traction [16]. The second case report concerned a classic Valsalva maneuver that triggered the bleeding. In contrast to the other case report, this patient suffered a much stronger subhyaloid hemorrhage. After draining the blood into the vitreous cavity, a

size is seen; green line shows the localization of the SD-OCT image of Fig. 5d. d SD-OCT of the foveal region: a dense subhyaloidal hemorrhage is recognizable, and the retina appears to be normal. SD-OCT spectral-domain optical coherence tomography

severe decrease in visual acuity occurred. The patient should be consented for a possible delay of visual recovery.

The treatment of subhyaloid hemorrhage may include waiting for spontaneous absorption, vitreal injection of rt-PA (recombinant tissue plasminogen activator) with gas, pars plana vitrectomy, or laser application (argon or Nd:YAG laser) [8-10, 13, 17]. Depending on the application (type of laser 


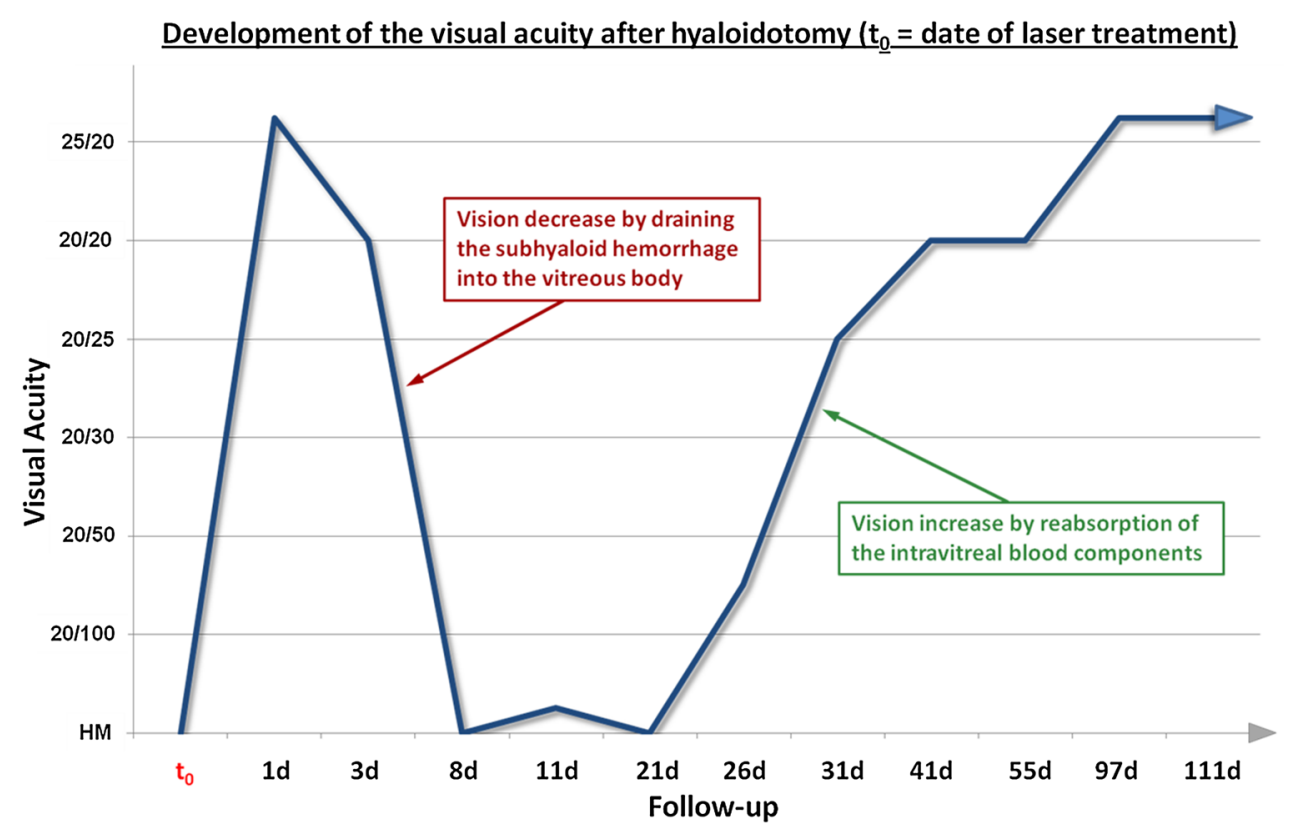

Fig. 5 Development of visual acuity over the course of time after hyaloidotomy. Operation at time $t_{0}$; afterwards, visual acuity increased rapidly. After approximately 1 week, the visual acuity dropped again to hand motions (HM), since the blood had drained into the vitreous body space. In the

and contact lens), the use of cumulative energies of up to $180 \mathrm{~mJ}$ has been described [18]. It is important that optimal conditions are present during this treatment. The patient must be cooperative, and the surgeon should be sure to obtain sufficient medical mydriasis. This reduces the danger of incident light dispersion, such as via the iris. Moreover, the viewing conditions for the surgeon can be improved. The laser beam should be directed through the center of the pupil, and a pupil width of at least $6 \mathrm{~mm}$ is necessary. Thereby, the needed energy can be reduced [4, 18].

NYLH in the context of subhyaloid hemorrhage represents a minimally invasive treatment option. It leads to a rapid increase in vision and is an inexpensive method of intervention. Complications have rarely been described. However, retinal defects as well as vitreal, intraretinal or subretinal and choroidal further 4 weeks, constant reabsorption of the blood with a corresponding increase in vision was seen. The presumed initial vision of $25 / 20$ was only reached after approximately 3 months

hemorrhages can occur [19-21]. Successfully applied, the subhyaloid hemorrhage drains into the vitreous body area, where it is optically less relevant and is better accessible for reabsorption. With a wait-and-see procedure, a convalescence of several months may be expected [4].

\section{CONCLUSIONS}

NYLH offers numerous advantages. The possibility of a rapid increase in vision (if no other macular pathologies present), the low rate of complications, the good availability, and low costs make laser hyaloidotomy a good treatment option for subhyaloid premacular hemorrhage. Nevertheless, certain circumstances should be considered. Serious underlying diseases should be excluded, and an optimal environment for the treatment is 
required. In cases of an observational approach to the findings, 3 months should not be exceeded. Modern OCT technology is exceptionally suited for diagnosis and evaluation during the clinical course.

\section{ACKNOWLEDGMENTS}

No funding or sponsorship was received for this study or publication of this article. All named authors meet the International Committee of Medical Journal Editors (ICMJE) criteria for authorship for this manuscript, take responsibility for the integrity of the work as a whole, and have given final approval for the version to be published.

Disclosures. Jens Heichel, Elisabeth Kuehn, Astrid Eichhorst, Thomas Hammer, and Iris Winter have nothing to declare.

Compliance with ethics guidelines. All procedures were in accordance with the ethical standards of the responsible committee on human experimentation (institutional and national) and with the Helsinki Declaration of 1964, as revised in 2013. Informed consent was obtained from the patients for being included in the study.

Open Access. This article is distributed under the terms of the Creative Commons Attribution-NonCommercial 4.0 International License (http://creativecommons.org/licenses/ by-nc/4.0/), which permits any noncommercial use, distribution, and reproduction in any medium, provided you give appropriate credit to the original author(s) and the source, provide a link to the Creative Commons license, and indicate if changes were made.

\section{REFERENCES}

1. Cleary PE, Kohner EM, Hamilton AM, Bird AC. Retinal macroaneurysms. $\mathrm{Br} \mathrm{J}$ Ophthalmol. 1975;59:355-61.

2. O'Hanley GP, Canny CL. Diabetic dense premacular hemorrhage. A possible indication for prompt vitrectomy. Ophthalmology. 1985;92:507-11.

3. Iijima H, Satoh S, Tsukahara S. Nd:YAG laser photodisruption for preretinal hemorrhage due to retinal macroaneurysm. Retina. 1998;18:430-4.

4. Rennie CA, Newman DK, Snead MP, Flanagan DW. Nd:YAG laser treatment for premacular subhyaloid haemorrhage. Eye (Lond). 2001;15:519-24.

5. Duane TD. Valsalva hemorrhagic retinopathy. Trans Am Ophthalmol Soc. 1972;70:298-313.

6. Kroll P, Busse H. Therapy of preretinal macular hemorrhages. Klin Monbl Augenheilkd. 1986;188:610-2.

7. Spraul CW, Grossniklaus HE. Vitreous hemorrhage. Surv Ophthalmol. 1997;42:3-39.

8. Brent BD, Gonce M, Diamond JG. Pars plana vitrectomy for complications of retinal arterial macroaneurysms - a case series. Ophthalmic Surg. 1993;24:534-6.

9. Hesse L, Schmidt J, Kroll P. Management of acute submacular hemorrhage using recombinant tissue plasminogen activator and gas. Graefes Arch Clin Exp Ophthalmol. 1999;237:273-7.

10. Schmitz K, Kreutzer B, Hitzer S, Behrens-Bauman W. Therapy of subhyaloidal hemorrhage by intravitreal application of rtPA and $\mathrm{SF}(6)$ gas. $\mathrm{Br} \mathrm{J}$ Ophthalmol. 2000;84:1324-5.

11. Heydenreich A. Treatment of preretinal haemorrhages by means of photocoagulation (author's transl). Klin Monbl Augenheilkd. 1973;163:671-6.

12. Küper KD, De Laey JJ, Herzeel R. Subhyaloid hemorrhage in association with an atypical central vein occlusion. Klin Monbl Augenheilkd. 2002;219:810-2.

13. Ulbig MW, Mangouritsas G, Rothbacher $\mathrm{HH}$, Hamilton AM, McHugh JD. Long-term results after drainage of premacular subhyaloid hemorrhage into the vitreous with a pulsed Nd:YAG laser. Arch Ophthalmol. 1998;116:1465-9.

14. McCarron MO, Alberts MJ, McCarron P. A systematic review of Terson's syndrome: frequency 
and prognosis after subarachnoid haemorrhage. J Neurol Neurosurg Psychiatry. 2004;75:491-3.

15. Rubenstein RA, Yanoff $M$, Albert DM. Thrombocytopenia, anemia, and retinal hemorrhage. Am J Ophthalmol. 1968;65:435-9.

16. Spitzer MS, Januschowski K. Aging and age-related changes of the vitreous body. Ophthalmologe. 2015;112:552-8.

17. Humayun M, Lewis H, Flynn HW Jr, Sternberg P Jr, Blumenkranz MS. Management of submacular hemorrhage associated with retinal arterial macroaneurysms. Am J Ophthalmol. 1998;126:358-61.

18. Nili-Ahmadabadi M, Lashay AR, Karkhaneh R, Manaviat MR, Amini A, Razaghi A, Alami Z.
Nd:YAG laser application in premacular subhyaloid hemorrhage. Arch Iranian Med. 2004;7:206-9.

19. Frankenhauser F, Kwasniewska S. Neodymium:yttrium-aluminium-garnet laser. In: L'Esperance FA, editor. Ophthalmic lasers, vol. II. St. Louis: CV Mosby; 1989.

20. Puliafito CA, Wasson PJ, Steinert RF, Gragoudas ES. Neodymium-YAG laser surgery on experimental vitreous membranes. Arch Ophthalmol. 1984;102:843-7.

21. Thach AB, Lopez PF, Snady-McCoy LC, Golub BM, Frambach DA. Accidental Nd:YAG laser injuries to the macula. Am J Ophthalmol. 1995;119:767-73. 